\title{
COVID-19 Pandemic: A comparison of adult and pediatric populations
}

\author{
Muhammed Emin Demirkol ${ }^{1}$, Musa Kaya $^{2}$, Mehmet Balci $^{3}, \quad$ Emine Ozsari $^{4}$ \\ ${ }^{1}$ Department of Internal Medicine, Bolu Abant Izzet Baysal University, Faculty of Medicine, Bolu, Turkey \\ ${ }^{2}$ Department of Emergency Medicine, Zonguldak Ataturk State Hospital, Zonguldak, Turkey \\ ${ }^{3}$ Department of Infectious Diseases, Izzet Baysal State Hospital, Bolu, Turkey \\ ${ }^{4}$ Department of Chest Diseases, Bolu Abant Izzet Baysal University, Faculty of Medicine, Bolu, Turkey
}

\section{ABSTRACT}

Aim: Couple of pneumonia cases were reported in a short period in Wuhan, China. The cases were revealed to be associated with a different coronavirus type was named SARS-CoV-2 and the disease was identified as Covid-19. It is known that the disease occurs in all age groups. We aimed to evaluate the differences in clinical and laboratory features between adult and pediatric patients.

Method: The study is a retrospective cross-sectional study and consists of 206 patients with a definitive diagnosis of Covid-19 confirmed by a positive real-time reverse-transcriptase polymerase chain reaction (RTPCR) testing for SARS-CoV-2. They hospitalized in health institutions connected to City Health Administrative of Bolu, Turkey between 11.03.2020 and 19.04.2020. The number of the pediatric patients (017 age group) was 106, that of the adult patients (18 and above age group) was 100. Data concerning the patients consisted of age, symptoms, laboratory parameters such as hemogram, biochemistry, coagulation.

Results: The mean values of platelet (PLT), platocrit (PCT), percentage of monocytes (MONO \%) and MONO in the "0-17" age group were found to be significantly higher than the mean values in the "18 and above" age group. The hemoglobin (HGB) mean value of the " $0-17$ " age group was significantly lower than that of the "18 and above" age group. The mean C - reactive protein (CRP) value of the "0-17" age group (4.55; min: 1.20 - max: 11.80) was significantly lower than that of the "18 and above" age group (5.35; min 1.25- max: 19.77) with no statistically significance. In pediatric group, the most common symptoms were other symptoms like diarrhea, vomiting and joint pain whereas the adult patients had fever and cough often with statistically significant.

Conclusion: Clinical findings and laboratory abnormalities in Covid-19 are less common in children. Although it seems that Covid-19 is less symptomatic in children, they are also affected by the disease. Performing RT-PCR test based on the contact history of the children may help to minimize morbidity with an early diagnosis. Multicenter studies with more numbers of patients should be performed.

Key words: COVID - 19, SARS-CoV-2, adolescent, adult, child.

$\triangle$ Dr. Emine Ozsari

Department of Chest Diseases, Bolu Abant Izzet Baysal University, Faculty of Medicine, Bolu, Turkey

E-mail: dreminedemirok@hotmail.com

Received: 2021-01-04 / Revisions: 2021-01-16

Accepted: 2021-04-19

Published online: 2021-07-01

\section{Introduction}

In December 2019, a couple of pneumonia cases were reported in a short period in Wuhan, China [1]. The cases were revealed to be associated with a different coronavirus type was named SARS-CoV-2 and the disease it caused was identified as Covid-19 [2]. While 
other types of coronavirus such as SARS-CoV and MERS-CoV do not lead to severe diseases, SARS-CoV-2 have caused millions of deaths $[3,4]$.

It is known that Covid-19 occurs not only in adults but also in children [5]. However, children represent a very small proportion of cases and prior studies have shown that the mortality rate is much lower in them $[6,7]$. Moreover, it has been determined that the clinical picture in children is considerably milder than in adults [8]. The disease is diagnosed mostly with fever, cough, sneezing, sore throat, myalgia, pharyngeal erythema and runny nose. However, symptoms such as diarrhea, nausea, vomiting and malaise can also be seen [9]. Compared to adults, frequent laboratory abnormalities such as elevated CRP and procalcitonin levels and lymphopenia were found to be quite low in children diagnosed with Covid-19 [10]. In this study, we aimed to evaluate the differences in clinical and laboratory features between adult and pediatric patients to diagnose more effectively.

\section{Materials and methods}

The study is a retrospective cross-sectional study and consists of 206 patients with a definitive diagnosis of Covid-19 confirmed by a positive RT-PCR test after hospitalized in health institutions connected to City Health Administrative of Bolu, Turkey between 11.03.2020 and 19.04.2020. Ethical approval of the study was obtained from Bolu Abant İzzet Baysal University Clinical Research Ethics Committee (Date: 12.05.2020, Number: 2020/92). Data was obtained by scanning the patients from the Public Health Management System of City Health Administrative and Hospital Information Management System. Information about the patients consisted of age, symptoms, results of laboratory parameters such as white blood cell count (WBC), hemoglobin (HGB), hematocrit (Htc), lymphocyte count (LYM), platelet count (PLT), red blood cell (RBC), basophil (BASO), platocrit (PCT), neutrophil (NEU),monocyte (MONO), D-DIMER, C-Reactive protein (CRP) and lactate dehydrogenase (LDH). Clinical findings categorized as fever, cough and other symptoms like diarrhea, vomiting, anosmia, headache, joint pain and sore throat. Patients who didn't apply during the mentioned dates were not included the study. Also pregnant women and patients with immunosuppressions, diabetes mellitus, chronic lung and kidney diseases, and hypertension were excluded.

\section{Statistical analyses}

For all statistical analyses, the 20.0 version of SPSS (Statistical Package for the Social Sciences) for Windows, (Chicago, Illinois, USA) was used. The numerical data were expressed as mean \pm standard deviation. The difference between the study and the control groups was evaluated by Student t-test for data which were normally distributed. For the data which were not normally distributed MannWhitney's U-test was used. Chi-Square test was used in the analysis of categorical data. The correlation between EFT and MS was evaluated using Spearman's correlation analysis. A $p$-value $<0.05$ was considered as significant.

\section{Results}

There were 206 patients in the study; 106 patients between 0-17 years, 100 patients aged 18 and above. The mean age was 13.52 (min: 1max: 17) in the "0-17" age group and 45.43 (min: 18-max: 85) in the "18 and above" age group $(p=0,000)$.

The mean values of PLT, PCT, MONO\% and MONO in the " $0-17$ " age group were found to 
be significantly higher than the mean values in the "18 and above" age group ( $p<0.05)$. The HGB mean value of the " $0-17$ " age group was significantly lower than that of the " 18 and above" age group $(p<0.05)$ (Table 1$)$. The mean CRP value of the " $0-17$ " age group (4.55; min: 1.20 - max: 11.80) was significantly lower than that of the " 18 and above" age group $(5.35$; $\mathrm{min}$ 1.25- max: 19.77) with no statistically significance $(p=0.461)$ (Table 1$)$.
The percentages of the clinical findings were calculated for both age groups. In the ' $0-17$ ', age group, the most common symptoms were other symptoms (54.8\%) like diarrhea, vomiting, anosmia, sore throat and joint pain. $(p=1.153)$ The presence of fever $(69 \%)$ and cough $(69.9 \%)$ symptoms was significantly higher in the 18 and above age group $(p=0.000)$ (Table 2).

Table 1. Laboratory results of age groups.

\begin{tabular}{|c|c|c|c|c|}
\hline \multicolumn{5}{|c|}{ Comparison of laboratory results between age groups } \\
\hline \multirow[t]{2}{*}{ Parameters } & $\begin{array}{c}\text { “0-17" age } \\
\text { group } \\
(\mathrm{n}=106 ; \% 51.5) \\
\end{array}$ & $\begin{array}{c}\text { '18 and above"' age } \\
\text { group } \\
(n=100 ; 48.5)\end{array}$ & All Patients & \multirow[t]{2}{*}{ p-value } \\
\hline & \multicolumn{3}{|c|}{ Median (Q1-Q3)** } & \\
\hline WBC & $5.83(4.77-7.39)$ & $5.50(4.50-6.59)$ & $5.76(4.57-7.03)$ & 0.062 \\
\hline LYM & $1.49(1.01-2.00)$ & $1.45(1.15-1.93)$ & $1.45(1.1-1.96)$ & 0.931 \\
\hline HGB & $13.50(13.00-14.40)$ & $14.25(12.80-15.40)$ & $13.70(13-14.90)$ & $0.024 *$ \\
\hline BASO & $0.02(0.01-0.03)$ & $0.034(0-0.06)$ & $0.03(0.01-0.05)$ & 0.390 \\
\hline PLT & $253.5(216-293)$ & $207.5(172.5-247.0)$ & $228.5(196-273)$ & $0.000 *$ \\
\hline PCT & $0.25(0.22-0.29)$ & $0.17(0.14-0.21)$ & $0.21(0.17-0.26)$ & $0.000 *$ \\
\hline NEU & $3.44(2.40-5.00)$ & $3.46(2.41-4.60)$ & $3.44(2.4-4.76)$ & 0.514 \\
\hline D-DİMER & $0.29(0.21-0.58)$ & $0.37(0.22-0.59)$ & $0.32(0.21-0.58)$ & 0.566 \\
\hline LDH & $234(207-283)$ & $222.5(185-273.5)$ & $230(196-276)$ & 0.073 \\
\hline CRP & $4.55(1.20-11.80)$ & $5.35(1.25-19.77)$ & $4.84(1.2-14.7)$ & 0.461 \\
\hline \multicolumn{5}{|c|}{$\bar{X} \pm s s^{* * * *}$} \\
\hline Age & $13.52 \pm 3.15$ & $45.43 \pm 17.26$ & $29.01 \pm 20.11$ & $0.000 *$ \\
\hline $\mathrm{RBC}$ & $4.88 \pm 0.45$ & $4.86 \pm 0.55$ & $4.87 \pm 0.49$ & 0.728 \\
\hline LYM\% & $27.09 \pm 13.41$ & $28.47 \pm 10.98$ & $27.76 \pm 12.28$ & 0.419 \\
\hline MONO\% & $11.31 \pm 3.85$ & $8.75 \pm 3.50$ & $10.07 \pm 3.89$ & $0.000 *$ \\
\hline NEU\% & $59.98 \pm 14.56$ & $61.39 \pm 12.02$ & $60.66 \pm 13.37$ & 0.447 \\
\hline MONO & $0.70 \pm 0.28$ & $0.50 \pm 0.25$ & $0.61 \pm 0.28$ & $0.000 *$ \\
\hline
\end{tabular}


Table 2. Chi-Square analysis of clinical findings according to age groups.

\begin{tabular}{|c|c|c|c|c|c|}
\hline Parameters & $\begin{array}{c}\text { “0-17” age group } \\
\text { (n:106; \%51.5) }\end{array}$ & $\begin{array}{c}\text { '18 and above"' age } \\
\text { group } \\
\text { (n:100; \%48.5) }\end{array}$ & $\begin{array}{l}\text { All Patients } \\
\text { (n:206) }\end{array}$ & $p$-value & $\chi^{2}$ value \\
\hline \multirow{2}{*}{$\begin{array}{l}\text { Fever } \\
\text { positive } \\
\text { negative }\end{array}$} & $48(\% 39.3)$ & $74(\% 69.0)$ & $122(\% 59.2)$ & \multirow{2}{*}{$0.000 *$} & \\
\hline & $58(\% 60.7)$ & $26(\% 31.0)$ & $84(\% 40.8)$ & & 17.572 \\
\hline \multirow{2}{*}{$\begin{array}{l}\text { Cough } \\
\text { positive } \\
\text { negative }\end{array}$} & $27(\% 29.0)$ & $79(\% 69.9)$ & $93(\% 45.1)$ & \multirow[t]{2}{*}{$0.000 *$} & 34.129 \\
\hline & $66(\% 71.0)$ & $34(\% 30.1)$ & $113(\% 54.9)$ & & \\
\hline \multirow{2}{*}{$\begin{array}{l}\text { Other } \\
\text { symptoms } \\
\text { positive } \\
\text { negative }\end{array}$} & $63(\% 54.8)$ & $52(\% 47.3)$ & $115(\% 55.8)$ & \multirow[t]{2}{*}{0.326} & \multirow[t]{2}{*}{1.153} \\
\hline & $43(\% 45.2)$ & $48(\% 52.7)$ & $91(\% 44.2)$ & & \\
\hline
\end{tabular}

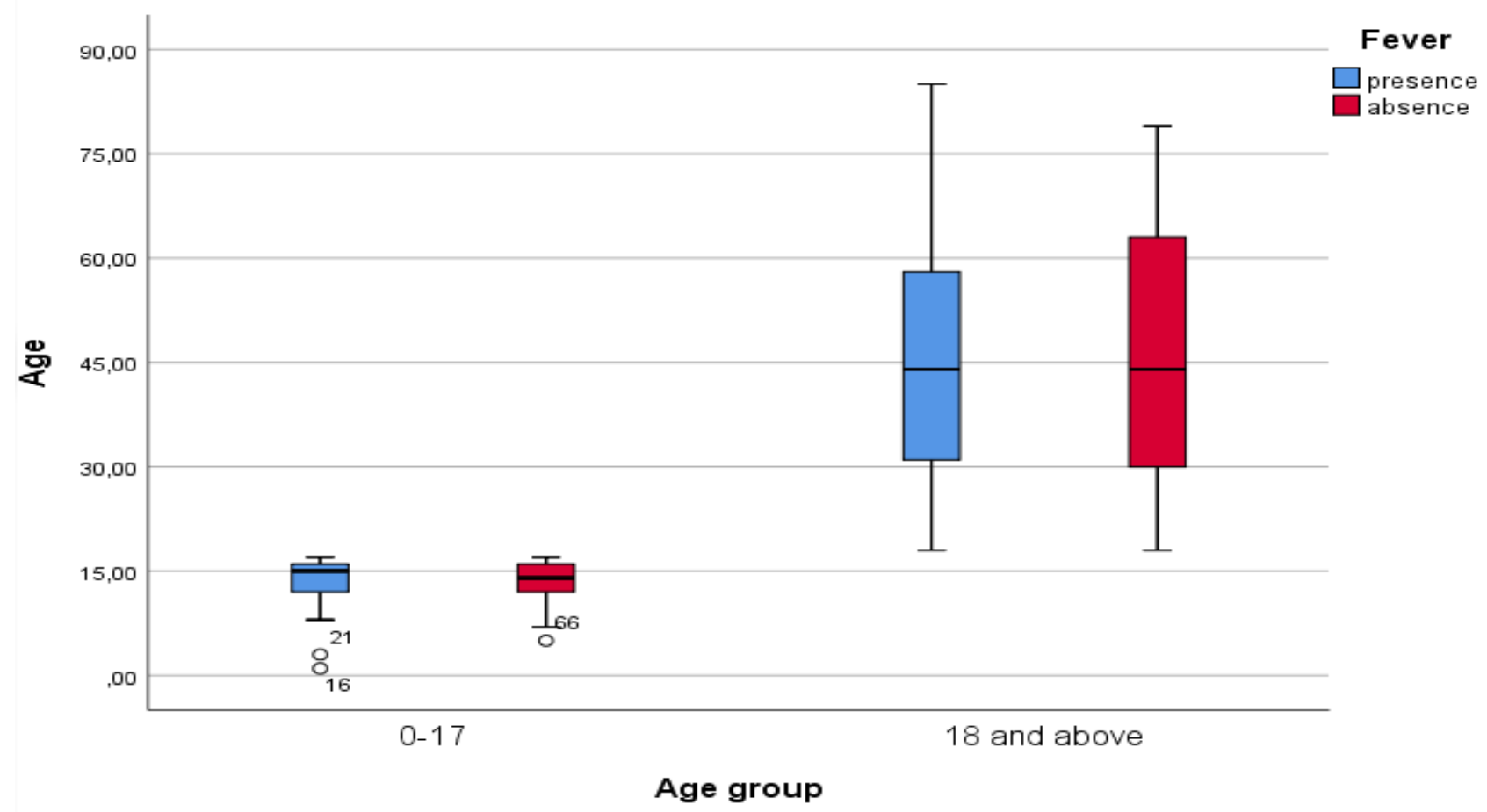

Figure 1. Relationship between age groups and fever.

\section{Discussion}

In this study, we aimed to reveal the differences in clinical and laboratory features between adult and pediatric patients and tried to emphasize that children are also at risk for Covid-19 as different manifestations.

It was observed that only $1.7 \%$ of the cases reported in United States of America (USA) until April 2020 were children. Despite the low incidence compared to adult patients, SARSCoV-2 is also seen in children and has been shown to be associated with milder clinical symptoms [11-13]. Of 206 patients in our study, 106 (\%51.5) were children, and the proportion was found to be quite higher according to USA data. We attributed this to the fact that children 
were scanned and caught at the stage without symptoms. While none of pediatric patients needed intensive care, 3 of the adult patients were followed up in intensive care unit. Among 100 adult patients $1(1 \%)$ death occurred, but no death was seen in children.

A study in China revealed that children had mild clinical symptoms and less need for intensive care compared to adults. In this study, the most common symptoms were cough (48.5\%), pharyngeal erythema $(46.2 \%)$ and fever $(41.5 \%)$. It was reported that only 3 of 171 patients needed intensive care and all of them had underlying diseases.[14] In our study, fever (39.3\%), cough $(29.0 \%)$ and other symptoms $(54.8 \%)$ like diarrhea, vomiting, anosmia, joint pain and sore throat were recorded in children (Figure 1) On the other hand, major symptoms of adults were fever $(69 \%)$ and cough $(69.9 \%)$ while other symptoms $(47.3 \%)$ noticed lower than children (Figure 2) In a Chinese study, 8 of 10 pediatric patients had fever and 6 of them had cough confirming most common symptoms in children were similar to those in adults [15]. In a study performed by Yang et al. [16] with 134 pediatric patients, the fever was found to be the most common symptom with $76.1 \%$.

In a study conducted by Chen et al. [17] with 505 patients of whom 12 were children, it has been shown that lymphopenia seen in only 2 patients was less common than adults. In our study, lymphopenia was similar in children as adults (mean LYM value in children: 1.49 mean LYM value in adults 1.45). (Table 1) Moreover, it has been shown that the mean LYM value was lower in adults compared to pediatric patients. Xia et al. [18] researched that; $70 \%$ of pediatric patients had normal WBC count, 20\% had leukopenia and $10 \%$ had leukocytosis. Additionally, lymphopenia (35\%), elevated alanine aminotransferase (ALT) (25\%), elevated CRP (45\%) and elevated procalcitonin $(80 \%)$ were the other laboratory abnormalities. In our pediatric patients; WBC, RBC, MONO, PLT, PCT and $\mathrm{LDH}$ were higher than adults whereas $\mathrm{Hb}$, BASO, NEU, D DIMER and CRP were lower than adults. Among these findings, while the increase of PLT, PCT, MONO\% and MONO and the decrease of $\mathrm{Hb}$ in the " $0-17$ " age group were statistically significant. $(\mathrm{p}<0.05)$ (Table $1)$.

There may some explanations for the reasons between the differences in clinical features between adults and children. One of the study has been suggested that the virus in children is the second, third and sometimes fourth generation because of the transmission of the disease from adults, and compared to the first generation one it is more difficult for the virus to replicate, mutate and survive before it is recognized by the immune system [19]. Furthermore, it has been argued that natural immunity in children is more ready against such pathogens and immune system functions decrease with aging $[19,20]$. Considering that there is a curfew for people under 20 years of age since the beginning of the outbreak in Turkey, it can be concluded that children get the disease from adult members of the family. In addition to this, the children had a history of indirect contact and the disease in children was less symptomatic, the above-mentioned opinions seem to be reasonable.

\section{Conclusion}

Clinical findings and laboratory abnormalities in Covid-19 are less common in children. Although it seems that Covid-19 is less symptomatic in children, they are also affected by the disease. Performing RT-PCR test based on the contact history of the children may help to minimize morbidity with an early diagnosis. Multicenter studies with more numbers of 
patients should be performed for more accurate outcomes.

Funding: The author(s) received no financial support for the research, authorship, and/or publication of this article.

Conflict of Interest: The authors declare that they have no conflict of interest.

Ethical statement: The study was approved by Bolu Abant İzzet Baysal University Clinical Research Ethics Committee (Date: 12.05.2020, Number: 2020/92), and written informed consent was obtained from each subject.

\section{Open Access Statement}

This is an open access journal which means that all content is freely available without charge to the user or his/her institution under the terms of the Creative Commons Attribution NonCommercial License (http://creativecommons.org/licenses/bync/4.0). Users are allowed to read, download, copy, distribute, print, search, or link to the full texts of the articles, without asking prior permission from the publisher or the author.

\section{References}

[1]Zhu N, Zhang D, Wang W, et al. China Novel Coronavirus Investigating and Research Team. A Novel Coronavirus from Patients with Pneumonia in China, 2019. N Engl J Med. 2020;382(8):727-33.

[2]World Health Organization.Novel coronavirus - China2020

https://www.who.int/csr/don/ 12-january2020-novel -coronavirus-china/en/).

[3]Huang C, Wang Y, Li X, et al ; Clinical features of patients infected with 2019 novel coronavirus in Wuhan, China. Lancet. 2020;395(10223):497-506.

[4]Chen N, Zhou M, Dong X, et al. Epidemiological and clinical characteristics of 99 cases of 2019 novel coronavirus pneumonia in Wuhan, China: a descriptive study. Lancet. 2020;395 (10223):507- 13.

[5]Ludvigsson JF. Systematic review of COVID-19 in children shows milder cases and a better prognosis than adults. Acta Paediatr. 2020 Jun;109(6):1088-1095.

[6]Novel Coronavirus Pneumonia Emergency Response Epidemiology Team. The Epidemiological Characteristics of an Outbreak of 2019 Novel Coronavirus Diseases (COVID-19) in China. Zhonghua Liu Xing Bing Xue Za Zhi. 2020;41(2):145151.

[7]Livingston E, Bucher K. Coronavirus Disease 2019 (COVID-19) in Italy. JAMA. 2020;323(14):1335.

[8]Dong Y, Mo X, Hu Y, Qi X, Jiang F, Jiang Z, Tong S. Epidemiology of COVID-19 Among Children in China. Pediatrics. 2020;145(6):e20200702.

[9]Henry BM, Lippi G, Plebani M. Laboratory abnormalities in children with novel coronavirus disease 2019. Clin Chem Lab Med. 2020;58(7):1135-38.

[10] Weiss SR, Leibowitz JL. Coronavirus pathogenesis. Adv Virus Res. 2011;81:85164.

[11]Zaki AM, van Boheemen S, Bestebroer TM, et al. Isolation of a novel coronavirus from a man with pneumonia in Saudi Arabia. N Engl J Med.2012;367(19):1814-20.

[12] Special Expert Group for Control of the Epidemic of Novel Coronavirus Pneumonia of the Chinese Preventive Medicine Association. [An update on the epidemiological characteristics of novel coronavirus pneumonia (COVID-19)]. Zhonghua Liu Xing Bing Xue Za Zhi. 2020;41(2):139-144.

[13]CDC COVID-19 Response Team. Coronavirus Disease 2019 in Children - 
United States, February 12-April 2, 2020. MMWR Morb Mortal Wkly Rep. 2020;69(14):422-26.

[14]Lu X, Zhang L, Du H, et al. Chinese Pediatric Novel Coronavirus Study Team. N Engl J Med. 2020; 382(17):1663-65.

[15]Jiehao C, Jin X, Daojiong L, et al. A Case Series of Children With 2019 Novel Coronavirus Infection: Clinical and Epidemiological Features. Clin Infect Dis. 2020;71(6):1547-51.

[16] Yang P, Liu P, Li D, Zhao D. Corona Virus Disease 2019, a growing threat to children? J Infect. 2020;80(6):671-93.

[17]Chen J, Zhang ZZ, Chen YK, et al. The clinical and immunological features of pediatric COVID-19 patients in China. Genes Dis. 2020;7(4):535-541.

[18] Xia W, Shao J, Guo Y, et al. Clinical and CT features in pediatric patients with COVID19 infection: Different points from adults. Pediatr Pulmonol. 2020 ;55(5):1169-74.

[19] Su L, Ma X, Yu H, et al. The different clinical characteristics of corona virus disease cases between children and their families in China - the character of children with COVID-19. Emerg Microbes Infect. 2020;9(1):707-13.

[20]Ruggiero A, Attinà G, Chiaretti A. Additional hypotheses about why COVID19 is milder in children than adults. Acta Paediatr. 2020;109(8):1690. 